\title{
Histone Chaperones: Functions beyond Nucleosome Deposition
}

\author{
Divya Reddy, Saikat Bhattacharya, Sanjay Gupta* \\ Epigenetics and Chromatin Biology Group, Gupta Lab., Cancer Research Institute, Advanced Centre for \\ Treatment, Research and Education in Cancer, Tata Memorial Centre, Navi Mumbai, India \\ Email: dvelga@actrec.gov.in, sbhattacharya@actrec.gov.in, ${ }^{*}$ sgupta@actrec.gov.in
}

Received 4 April 2014; revised 5 May 2014; accepted 15 May 2014

Copyright (C) 2014 by authors and Scientific Research Publishing Inc.

This work is licensed under the Creative Commons Attribution International License (CC BY).

http://creativecommons.org/licenses/by/4.0/

(c) (i) Open Access

\begin{abstract}
Histones, the structural unit of chromatin, must be assembled/dissembled to preserve or change chromatin organization in accordance to cellular needs. Initially, function of histone chaperones was thought to be only "histone carriers/vehicles", but now with accumulating evidences they are known to be the key actors of histone metabolism. With this outburst of knowledge, histone chaperones are now placed at the center of gene regulation, having roles to play in DNA replication, repair and transcription. This review will focus on the current knowledge we have about the role of histone chaperones in regulating cellular processes and their relation to disease. In addition, we discuss the potential of histone chaperones as a therapeutic target.
\end{abstract}

\section{Keywords}

\section{Histones, Chromatin, Cancer, Therapeutic Target}

\section{Introduction}

If the DNA of all the cells of a human body is joined end to end, it can cover the distance from the sun to the Pluto and back. It was always a matter of interest to understand how the DNA of a cell which is over a meter long is packaged inside the nucleus only about 10 microns in diameter. Later, it was found that basic proteins called "histones" play a major role in packaging of DNA, in a very orderly fashion so that it can be unwound quickly when required in specific foci, and then wound back without getting into a tangle. During compaction, at first 147 bp of DNA is wrapped around histone octamer comprising 2 each of histones H2A, H2B, H3, H4, thus giving rise to nucleosome core particle (NCP)—a basic unit of chromatin [1]. This conformation achieved is also known as "beads on a string structure" or 10-nm chromatin fibre. The nucleosome assembly occurs in an

"Corresponding author.

How to cite this paper: Reddy, D., Bhattacharya, S. and Gupta, S. (2014) Histone Chaperones: Functions beyond Nucleosome Deposition. Advances in Bioscience and Biotechnology, 5, 546-556. http://dx.doi.org/10.4236/abb.2014.56064 
orderly fashion. First H3/H4 tetramers are deposited on DNA, thus marking the site for NCP formation (nucleosome positioning) followed by deposition of two H2A/H2B dimers [2]. Then linker histone $\mathrm{H} 1$ seals off the NCP by sitting at the entry and exit site of DNA in the octamer. This leads to further compaction giving rise to the 30-nm chromatin fibre [3]. This structure further folds on itself with the help of other non-histone proteins ultimately leading to the formation of the highly compact metaphase chromosome. The disassembly of nucleosome follows the same events in a reverse order.

What recruits the $\mathrm{H} 3 / \mathrm{H} 4$ tetramer and the $\mathrm{H} 2 \mathrm{~A} / \mathrm{H} 2 \mathrm{~B}$ dimer onto the DNA? How do the disassembly of NCP achieve? What prevents the histones? Which are highly basic in nature to form non-specific aggregates within themselves and with DNA? Which is negatively charged? All these functions are carried out by a class of proteins designated as histone chaperones.

Quite a few histone chaperones have been characterized and the last decade has seen the discovery of many novel histone chaperones. Besides the discovery of new chaperones in recent years, an outburst of knowledge about histone chaperones in relation to gene regulation and disease has been seen. The same can be said about the parcel of the chaperones, the histones and their variants. This review will focus on the current knowledge we have about the role of histone chaperones in DNA replication, repair and transcription followed by their role in regulating cellular processes and their relation to disease. Further, we discuss the potential of using histone chaperones as a therapeutic target.

\section{Histone Chaperones: The Efficient Molecular Couriers}

Histones being highly basic in nature are designed to bind to a variety of DNA sequences. However, it was discovered that octamer has got a propensity to bind preferentially to certain DNA sequences like that to a sequence contained within 5S RNA gene of sea urchin [4]. This preference is also apparent in in vitro nucleosomal array reconstitution experiments using the salt dialysis method in which equally spaced arrays are formed only when positioning sequences like Widom 601 are used [5]. This preference possibly has to do with the bendability of the DNA sequence. However, despite the presence of heterogeneous DNA sequence in living organisms equally spaced arrays are formed with the aid of histone chaperones and chromatin remodelling complexes. In in vitro systems also when a chaperone like NAP1 is added evenly spaced arrays are formed [6], demonstrating that the histone chaperones clearly have the ability to form nucleosomes irrespective of sequence preference.

Histone chaperones can be illustrated on the basis of their histone binding selectivity and thus deposition, using which they can be differentiated into those favorably interacting with H3-H4 from those that prefer H2A-H2B. Some of the very well-studied chaperones of H2A/H2B includes Nap-1 (nucleosome assembly protein-1), first identified in HeLa cell extracts as an activity that facilitates the in vitro reconstitution of nucleosomes using pure histones in combination with other factors. Another H2A/H2B chaperone is FACT (Facilitates Active Chromatin Transcription) complex composed of two subunits hSpt16 and SSRP1, identified initially as a factor indispensable for transcriptional elongation through chromatin [7]. Later it has been shown to form stable complexes with the histone H2A-H2B dimer and functions through restructuring of nucleosomes within the ORFs of actively transcribed genes [8]. Examples of H3/H4 chaperones are CAF-1 (Chromatin Assembly Factor) complex consisting of three subunits: p150, p60 and p48 [9], formerly identified by complementation as a factor participating in the assembly of chromatin during SV40 origin-dependent DNA replication in human cell extracts. N1/N2 is also an $\mathrm{H} 3 / \mathrm{H} 4$ chaperone, isolated first from oocytes of $X$. laevis. Later on its homologs were discovered in budding and fission yeast [10]. Apart from the core histones, linker histone H1 also has a chaperone-NASP (Nuclear Autoantigenic Sperm Protein), aiding its deposition on to the DNA.

Apart from showing selectivity towards different core histones, some chaperones are also known to be specific towards certain H3 and H2A isoforms/variants. These chaperones specially bind either replicative variants, which form the bulk of the histone pool, are expressed and deposited in a replication-coupled manner during $\mathrm{S}$ phase of cell cycle, or replacement variants, which are expressed and incorporated in a replication-independent fashion. The best studied examples of such specificity are chaperones CAF-1 and HIRA (Histone Regulator A) preferentially depositing H3.1 (replication coupled) and H3.3 (replication independent) respectively [11]. Other histone variant specific chaperones include Chz1 (Chaperone of H2A.Z/H2B) of yeast [12], ANP32E a specific H2A.Z chaperone in humans [13], DAXX and DEK for chaperoning H3.3 histones [14]. Although examples of preferential chaperone-histone interaction exist, one should not undermine those chaperones which bind to multiple histones in a specific manner. For example, Nap1 despite being a H2A/H2B chaperone binds to linker histone in X. laevis eggs [15]. Similarly, nucleoplasmin, a H2A/H2B chaperone binds to linker histones and re- 
moves them from sperm and somatic chromatin during fertilization and early development [16]. The same is also observed for Nucleophosmin (NPM-1) which interacts with histones H3/H4 and H1 [17].

This raises the question of how histone chaperones interact with histones. Many chaperones like nucleoplasmin, yeast Asf1, yeast Nap1, the Spt16 subunit of FACT and nucleolin contain long acidic amino acid stretches with which they interact with basic histones leading to charge neutralization [18]. However, charge neutralization does not justify for the specificity of the histone-chaperone interaction and it cannot be the universal phenomenon for all the chaperones as, mammalian Asf1 and Drosophila Nap-1 lacks an acidic tail [19]. Therefore, it could be that these acidic regions may assist in strengthening histone-chaperone interaction. May be due to this reason, Nap-1 undergoes extensive polyglutamylation [20], also Nap-1 is known to aid in nucleosome assembly by eliminating the non-nucleosomal histone DNA interactions. Other chaperones like Asf-1, CAF-1 and HIRA are known to contain a conserved hydrophobic $\beta$-structure, which facilitates interaction with $\mathrm{H} 3 / \mathrm{H} 4$ [21]-[23]. Similar structure is also seen in H2A/H2B chaperones SET/TAF-1b and Nap-1, mutational studies have implicated that this conserved $\beta$ sheet may be the primary histone recognition motif in these chaperones [24]. For more extensive examples of how chaperones recognize their target readers may refer to some other well written review [25].

\section{Only a Vehicle or More?}

Formerly chaperones were thought to be as mere "histone carriers/vehicles" but now with accumulating evidence they are known to be key players at all phases of histone existence. Chaperones interact with histones upon their synthesis thus preventing their aggregation and interaction with other cellular moieties. Also guide them into the nucleus, and help in their specific association with DNA during different processes involving DNA-replication, repair and transcription (discussed in detail below). They bring about these varied functions by interacting with many cellular factors with the help of which they determine the site and position of nucleosome assembly/disassembly and thus affecting gene regulation. Therefore, from being just an observer to an active participant, chaperones have evolved as the crucial component in maintaining chromatin integrity and dynamics.

\subsection{Histone Chaperones: Role in DNA Replication and Repair}

Chromatin acts as a barrier for the DNA pol and RNA pol enzymes for replication and transcription respectively. Hence, for genome duplication the nucleosomes should be dissembled first and once the replication fork has progressed and daughter strands have been synthesized they should be assembled back. The same is consistent for transcription. During replication the hexameric MCM2-7 helicase unwinds double-stranded DNA to facilitate the progress of DNA polymerase. In doing so it disrupts existing nucleosomes, releasing histones. With the aid of its interaction with Mcm4, FACT chaperone complex picks up evicted H2A/H2B dimer [26]. Similarly Asf1 chaperone through its interaction with MCM complex takes up H3-H4 [27]. The existence of both chaperones at the replication fork is critical as FACT accelerates the unwinding activity of MCM and promotes formation of DNA replication origins [28]. Similarly, depletion of Asf1 has been shown to impair MCM helicase activity [27]. Once the DNA pol has passed, chaperones transfer parental histones back on to DNA and thus assembling nucleosomes. The Asf1-MCM interaction ensures accurate deposition of parental histones. Any inaccurate deposition may lead to loss of parental histone post-translational modifications (PTMs) involved in epigenetic silencing of gene expression [29]. In addition to parental histone transfer, histone chaperones promptly deposit newly synthesized histones onto nascent DNA. While deposition, chaperones also modulate, directly or indirectly, histone posttranslational modifications (PTMs). For example, the association between $\mathrm{H} 3-\mathrm{H} 4$ and Asf1 is required for acetylation of H3 lysine 56 (H3K56) by the Rtt109 acetyl transferase [30]. Following acetylation, the H3-H4 dimers are transferred to the next set of chaperones, CAF-1 and Rtt106, which then deposit the histones onto nascent DNA by their interaction with PCNA (proliferating cell nuclear antigen), known to be a processivity factor for DNA polymerases [31]. Thus, incorporation of new histones into nucleosomes is a carefully designed process carried out by a chain of histone chaperones.

There are no evidences of histone chaperones playing a dynamic role in chromatin disassembly process for the repair of double-strand break or a UV lesion. This is in disparity with DNA replication, where the lack of histone chaperones inhibits DNA replication. However, this does not exclude a role of histone chaperones as histone acceptors during the chromatin disassembly coupled to DNA repair. After nucleotide excision repair, the 
nucleosome reassembly near the repair site is done by the human $\mathrm{H} 3 / \mathrm{H} 4$ histone chaperones Asf1 and CAF-1 in a process similar to that of DNA replication [32].

\subsection{Histone Chaperones: Role in DNA Transcription}

A genome-wide loss of nucleosomes in the regulatory region is seen upon transcriptional activation suggesting that nucleosome depletion is a key factor involved in transcription [33]. Histone chaperones like FACT, also known as RNA polymerase II elongation complex, are involved in the rearrangement of histones $\mathrm{H} 2 \mathrm{~A} / \mathrm{H} 2 \mathrm{~B}$ during transcriptional activation. How this disassembly and reassembly is regulated and coordinated with polymerase passage is still not very well understood. It is speculated that phosphorylation of the C-terminal domain (CTD) of the RNA polymerase (RNAP) II and posttranslational modifications of histones play a central role [34]. After the elongating polymerase has passed the promoter, it is phosphorylated by the Ctk1 kinase on Serine (Ser) 2 of the CTD [35]. This phosphorylated Ser 2 recruits the Set2 methyltransferase which then methylates H3 K36 (H3 K36Me), leading to the recruitment of the small Rpd3 (Rpd3S), a histonedeacetylase (HDAC) complex [36]. Once recruited, it leads to deacetylation of H3 and H4 thereby promoting chromatin reassembly and compaction. Throughout this process histone chaperones Nap-1 and Vsp75 interact with Ctk-1 kinase and Set2 [37]. This rapid reassembly is very important because any delay may lead to transcription from cryptic initiation sites present with ORFs, which may interfere with normal programming of the cell [38]. Another important prerequisite for rapid assembly is if long stretches of naked DNA are left out they may form R-loops, in which RNA transcripts are hybridized back to its template DNA strand, an important source of genomic instability [39]. Cells also have evolved a backup plan to avoid such deleterious effects. Histone chaperone HIRA deposits specialized histone variant H3.3 in the regions which are actively transcribed [40]. This in part is facilitated because ASF1 travels with the transcription machinery and/or rapidly fills in the gaps left in nucleosome arrays following passage of RNA polymerase by donating H3.3 to HIRA [41]. Therefore, in combination with reassembly of parental histones, incorporation of histone variants help to cover up DNA after transcription.

\section{Histone Chaperones in Regulating Cellular Functions}

The barcoding of genome with proper histone variants especially H3 variants safe guards the cellular memory of the transcriptional status of genes which can be inherited across generations [42]. In this regard, it can be considered that histone chaperones responsible for the deposition of histone variants, play an active role in the remodeling of the chromatin domains in accordance to cell-type specific gene expression patterns. Indeed, as expected HIRA, a histone chaperone of H3.3 along with depositing H3.3 in a replication independent manner at transcriptionally active loci also plays a role in cellular processes like skeletal myogenesis [43]. In response to differentiation signals, rapid accumulation of H3.3 is seen in enhancer regions and promotor regions of MyoD gene, leading to loss of $\mathrm{H} 1$, opening of chromatin, and eventual acceleration of transcription initiation at MyoD gene locus [44]. Upon their expression DNA binding transcription factors MyoD and Mef2, recruit ATP-dependent chromatin-remodeling complexes and histone-modifying enzymes for the activation of muscle genes [45]. The role of HIRA in muscle differentiation is more evident when HIRA-null mice die between embryonic days 10 and 11 with a wide range of phenotypes caused by defective mesendodermal tissues [46]. HIRA and H3.3 also play a major role in the early steps of osteoblastic differentiation [47]. Also, in response to angiogenic signal, levels of H3K56 acetylation is increased within endothelial cells, at the chromatin domains of Vegfr 1 , Fgf1 and Pdgfa (angiogenic genes) via a HIRA-mediated histone H3 exchange [48]. Not only in myogenesis and angiogenesis, recent genome-wide analysis of H3.3 has shown many upstream regulatory enhancers enriched with H3.3, signifying the site specific and regulated deposition of H3.3 by HIRA [14]. The assembly of histone variant H3.3, into nucleosomes by the replication-independent pathway is mediated by multiple histone chaperones, including HIRA (as discussed above), DAXX (death domain-associated protein) and DEK. H3.3 chaperones, DEK and DAXX are involved in the deposition and exchange of H3.3 at telomeres and regulatory elements [49]. DAXX along with the chromatin-remodeling factor ATRX (alpha thalassemia/mental retardation syndrome X-linked) regulates H3.3 deposition at telomeric heterochromatin regions [50]. DEK plays a major a role in maintaining heterochromatin integrity through its interaction with HP1 $\alpha$ [51]. These facts conclude that H3.3 deposition at diverse chromatin regions occurs by distinct histone chaperones. Thus chaperones play an important role in gene expression by altering the chromatin environment locally by depositing their respective histone variants. 


\section{Histone Chaperones and Human Disease}

Any mis-positioning of nucleosomes on to a stretch of DNA results in defect in gene expression and at times genome instability and cancer. Therefore, it is not incorrect to assume that mis-regulation of histone chaperones or histone-modifying enzymes regulating nucleosome assembly/disassembly may stimulate development of human disease (Figure 1). Here we discuss few reports highlighting the role of histone chaperones in disease pathogenesis and their potential to be used as a therapeutic marker. Proliferation is one of the key physiological characters of cancer. Indeed few of histone chaperones are known to be highly expressed in proliferating cells. For instance-Asf1b, an isoform of Asf1 in mammalian cells, is essential for cell proliferation as seen to be down regulated in senescent cells. When its levels were checked in various breast cancer cell lines a correlation was observed with a proliferative status of cells, with more expression in highly proliferative cells. The same association was seen with breast cancer patients and is related to increased metastasis and shorter survival of breast cancer patients [52]. Apart from Asf1b, CAF-1 is also known to be highly expressed in breast cancer tissues and in prostate cancers [53]. CAF-1 p60 levels also correlated significantly in many solid tumors with disease stage, especially in renal, endometrial and cervical cancer patients [54]. A splice variant of NASP, tNASP also has been shown to be expressed in high levels in cancer, germ, transformed, and embryonic cells. When its expression was reduced in prostate cancer cell line PC-3 and in HeLa, inhibition of proliferation, increased levels of p21 and apoptosis was seen [55].

FACT complex (H2A/H2B chaperone) is expressed at higher levels in tumor cell lines than in normal cells in vitro and its knockdown lead to reduced growth and survival of tumor cells [56]. In addition, FACT expression was found to be elevated during the development of mammary carcinomas in transgenic mice expressing the Her2/neu protooncogene [57]. Genome-wide analysis for FACT distribution in tumor cells has identified a subset of genes that have activities associated with malignancy and stem-like properties of tumor cells and cellular stress responses. Also FACT expression is seen to be elevated upon in vitro transformation of fibroblasts and epithelial cells by various agents indicating its requirement for transformation, but its overexpression cannot substitute for the requirement of H-Ras ${ }^{\mathrm{V} 12}$. Therefore FACT cannot act as an oncogene but can still accelerate malignancy by providing certain chromatin changes which still needs to be elucidated. Moreover its expression can be significantly correlated with aggressiveness of cancers as elevated expression is seen during metastasis of

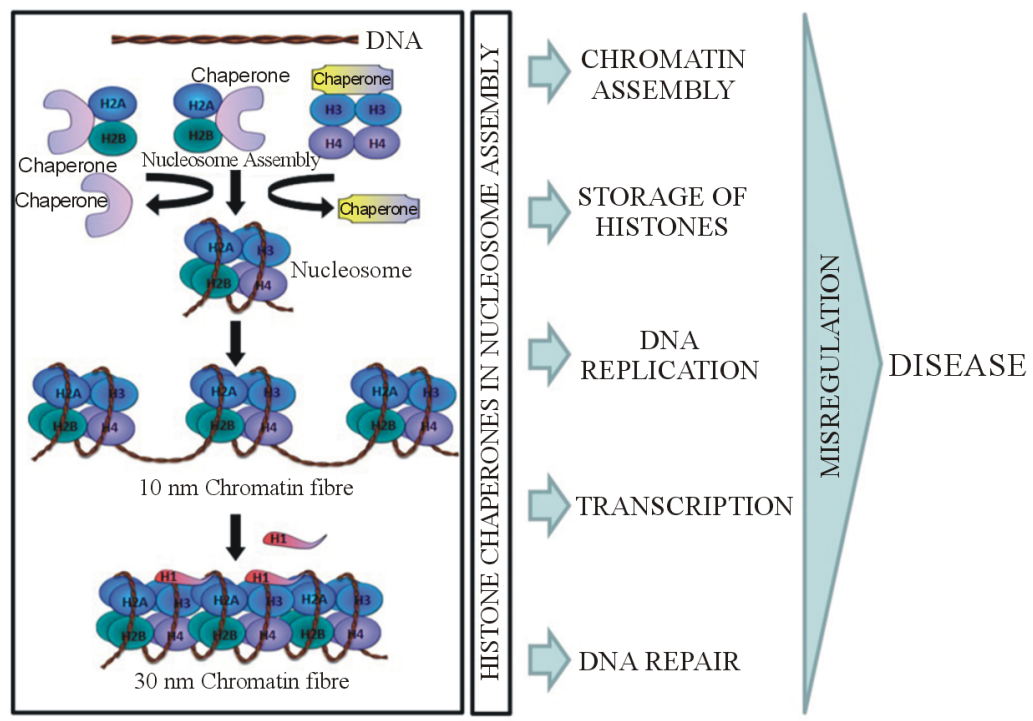

Figure 1. Chaperone and disease. Histone chaperones bind to their respective histone molecules and deposit them on to DNA template, leading to formation of nucleosome, repeating units of which join together to form a $10 \mathrm{~nm}$ chromatin fibre and upon $\mathrm{H} 1$ deposition a $30 \mathrm{~nm}$ chromatim structure is formed thus leading to compaction of DNA. By playing a major role in chromatin assembly, chaperones act as a central to DNA replication, repair and transcription. Thus, any misregulation in the levels of these proteins or any mutation in them leads to disease. 
breast, renal, and prostate cancer [58]. Mutations in another H2A/H2B chaperone Nap-1 have also been associated with many human cancers. NPM1 (chaperone for H3/H4 and H1) play a role in ribosome assembly, inhibition of pro-apoptotic pathways, maintenance of genomic stability. It has also been known to interact with the tumor suppressor protein p53, Rb, and ARF and also many other viral proteins [59]. Also is significantly abundant in tumor and growing cells compared to normal cells, hence used as a tumor marker and also known to be a putative proto-oncogene [60]. NPM1 mutations are common in acute myeloid leukemia (AML) which is characterized by abnormal NPM1 accumulation in the cytoplasm [61]. Survival of NPM-negative colorectal cancer patients be likely to be better than those for patients with NPM-positive lesions [62].

Overexpression of the DEK, a histone chaperone for $\mathrm{H} 3.3$ has been reported in a number of cancers like glioblastoma, melanoma, colorectal and bladder carcinoma and is known to play major role in promoting epithelial transformation. DEK inhibits senescence and apoptosis via the destabilization of p53, hinting its role in carcinogenesis. In human promyelocytic HL-60 cells differentiation led to DEK down regulation [63]. Conversely, upon overexpression of the DEK, differentiation programs can be neutralized, favoring oncogenic transformation [63]. A direct proof of DEK as "oncogene" has developed when it was seen that papilloma formation was significantly decreased in DEK knockout mice compared to wild type animals and heterozygote controls [64]. It also forms a fusion protein with calcium-dependent phosphatase calcineurin (CAN) owing to chromosomal translocation which has been detected in acute myeloid leukemia (AML) [65]. This fusion results in reduced interactions of DEK with H3.3 aiding in the recruitment of HP1 and thus promoting leukemia progression through misregulation of transcriptional repression [51]. Amplifications and copy number increase of the DEK gene were also found in a variety of malignancies, particularly in bladder cancer, melanoma and retinoblastoma [66].

Apart from overexpression, certain mutations within chaperones and their associated proteins have also been related to cancer. Mutations in Daxx-ATRX-H3.3 pathway have been observed in pancreatic neuroendocrine tumors [67]. Such mutations have also been identified in pediatric glioblastoma tumor samples. Because of their high incidence these mutations are now called as the "driver mutations" for promoting cancers [68]. In addition to cancer, misregulation of histone chaperones has also been reported in other diseases. In DiGeorge syndrome (DGS), small region of six HIRA genes located on Chromosome 22 is frequently deleted resulting in reduced levels of HIRA production [69]. It has been reported that reduction of HIRA in animal model systems leads to persistent truncusarteriosus, a phenotypic change associated with DGS [70], suggesting that HIRA haploinsufficiency contributes to the development of DGS.

\section{Concluding Remarks}

Histone chaperones play a central role in governing many of the cellular functions and hence disease (specific chaperones are exemplified in Table 1). In this era of modern medicine where targeted therapies are being looked upon as the new ray of hope to win long fought battles against diseases like cancer, targeting histone

Table 1. Histone chaperones, functions and their implications in disease.

\begin{tabular}{|c|c|c|c|}
\hline $\begin{array}{l}\text { Histone } \\
\text { chaperone }\end{array}$ & Functions & Implication in disease & $\begin{array}{l}\text { Reference } \\
\text { number }\end{array}$ \\
\hline Asf1 & $\begin{array}{c}\text { Histone import, histone transfer to CAF-1 and } \\
\text { HIRA, regulation of H3K56ac }\end{array}$ & Increased in breast cancer & $28,31,44,58$ \\
\hline CAF-1 & $\begin{array}{l}\text { H3.1-H4 deposition, } \\
\text { heterochromatin formation, repair }\end{array}$ & $\begin{array}{l}\text { Increased in renal, endometrial and } \\
\text { cervical cancer }\end{array}$ & $12,33,46,59$ \\
\hline DAXX & H3.3-H4 deposition at telomeric heterochromatin & $\begin{array}{c}\text { Mutated in pancreatic neuroendocrine and } \\
\text { glioblastoma }\end{array}$ & $55,56,68$ \\
\hline DEK & $\begin{array}{l}\text { H3.3-H4 deposition, maintenance of } \\
\text { heterochromatin }\end{array}$ & $\begin{array}{l}\text { DEK-CAN fusion due to chromosomal } \\
\text { translocation in AML }\end{array}$ & $55,57,66,67$ \\
\hline NASP & H1 and H3/H4 supply and turnover & Increased in prostate cancer & 11,60 \\
\hline NPM & $\begin{array}{l}\text { H1 and H3/H4 deposition, ribosome assembly, } \\
\text { genomic stability }\end{array}$ & Mutated in AML patients & $18,64,65$ \\
\hline FACT & H2A/H2B deposition, Transcription & $\begin{array}{l}\text { Increased during metastasis of breast, } \\
\text { renal, and prostate cancer }\end{array}$ & $7,61,62,63$ \\
\hline
\end{tabular}


chaperones may be a new weapon in the armory. Histone chaperones Asf1b, CAF-1p60 and tNASP are highly correlated with proliferating cells and with many cancers. Therefore these can be used as new proliferation markers of interest for early detection of a wide range of cancers, and can also be used as a powerful prognostic marker for occurrence of metastasis. Knockdown of tNASP resulted in inhibition of proliferation and apoptosis [55], leading us to consider them not only as prognostic markers, but also as a target of diagnostic importance. Another histone chaperone which has been in the limelight in recent years for its correlation with cancer is the FACT complex. Levels of FACT complex increase in certain cancers, based on which they can be divided into FACT positive and negative cancers. Survival of patients with FACT-positive tumors was significantly less than that of patients with FACT-negative tumors. Also, within these FACT-positive cancers, the levels of expression are very different; the more the expression of FACT, the more aggressive is the cancer. Link between FACT expression and metastasis is corroborated by the reports of levels of FACT to be significantly correlated with metastasis of breast, renal, and prostate cancer [58]. Hence it can act as a promising marker and target for those cancers characterized by high aggressiveness and poor prognosis. As FACT expression is absent/less in most normal cells/tissues, pharmacological inhibition of FACT could be a safe and operative strategy to treat those types of cancer for which there are very few treatment modalities.

Not only can the levels of chaperones, but also mutations in these proteins contribute towards disease progression. Using deep sequencing technology, mutations have been found in the H3.3/ATRX-DAXX pathway in pediatric glioblastoma tissue samples. As these mutations are very specific to cancer, drugs can be developed for targeting specifically such cancers. Even though many intricate details of how these mutations in chaperones and related proteins lead to human diseases are still in the dark, but with the advent of recent technologies it is hopefully just a matter of time for these to be revealed and targeted. However, before using them as therapeutic targets, further understanding is needed to determine whether the altered abundance of histone chaperones observed in human cancers is the consequence or the cause of tumorigenesis. Nonetheless, it leads us to hypothesize for the role of histone chaperones as a promising molecular target for therapies aiming to reverse epigenetic alterations in various diseases.

\section{Acknowledgements}

The authors are grateful to all members of Gupta Lab, ACTREC for valuable discussions. Special thanks to Mr. Shyam Chavan for helping in drawing figure. D.R and S.B are supported by CSIR fellowship.

\section{References}

[1] Luger, K., Mader, A.W., Richmond, R.K., Sargent, D.F. and Richmond, T.J. (1997) Crystal Structure of the Nucleosome Core Particle at 2.8 A Resolution. Nature, 389, 251-260. http://dx.doi.org/10.1038/38444

[2] Smith, S. and Stillman, B. (1991) Stepwise Assembly of Chromatin during DNA Replication in Vitro. EMBO Journal, 10, 971-980.

[3] Thoma, F., Koller, T. and Klug, A. (1979) Involvement of Histone H1 in the Organization of the Nucleosome and of the Salt-Dependent Superstructures of Chromatin. Journal of Cell Biology, 83, 403-427. http://dx.doi.org/10.1083/jcb.83.2.403

[4] Panetta, G., Buttinelli, M., Flaus, A., Richmond, T.J. and Rhodes, D. (1998) Differential Nucleosome Positioning on Xenopus Oocyte and Somatic 5 S RNA Genes Determines Both TFIIIA and H1 Binding: A Mechanism for Selective H1 Repression. Journal of Cell Biology, 282, 683-697.

[5] Lowary, P.T. and Widom, J. (1998) New DNA Sequence Rules for High Affinity Binding to Histone Octamer and Sequence-Directed Nucleosome Positioning. Journal of Cell Biology, 276, 19-42.

[6] Verreault, A. (2000) De Novo Nucleosome Assembly: New Pieces in an Old Puzzle. Genes \& Development, 14, 1430-1438.

[7] Orphanides, G., LeRoy, G., Chang, C.H., Luse, D.S. and Reinberg, D. (1998) FACT, a Factor That Facilitates Transcript Elongation through Nucleosomes. Cell, 92, 105-116. http://dx.doi.org/10.1016/S0092-8674(00)80903-4

[8] Orphanides, G. and Reinberg, D. (2000) RNA Polymerase II Elongation through Chromatin. Nature, 407, 471-475. http://dx.doi.org/10.1038/35035000

[9] Smith, S. and Stillman, B. (1989) Purification and Characterization of CAF-I, a Human Cell Factor Required for Chromatin Assembly during DNA Replication in Vitro. Cell, 58, 15-25. http://dx.doi.org/10.1016/0092-8674(89)90398-X 
[10] De Robertis, E.M., Longthorne, R.F. and Gurdon, J.B. (1978) Intracellular Migration of Nuclear Proteins in Xenopus Oocytes. Nature, 272, 254-256. http://dx.doi.org/10.1038/272254a0

[11] Tagami, H., Ray-Gallet, D., Almouzni, G. and Nakatani, Y. (2004) Histone H3.1 and H3.3 Complexes Mediate Nucleosome Assembly Pathways Dependent or Independent of DNA Synthesis. Cell, 116, 51-61. http://dx.doi.org/10.1016/S0092-8674(03)01064-X

[12] Luk, E., Vu, N.D., Patteson, K., Mizuguchi, G., Wu, W.H., Ranjan, A., Backus, J., Sen, S., Lewis, M., Bai, Y. and Wu, C. (2007) Chz1, a Nuclear Chaperone for Histone H2AZ. Molecular Cell, 25, 357-368. http://dx.doi.org/10.1016/j.molcel.2006.12.015

[13] Obri, A., Ouararhni, K., Papin, C., Diebold, M.L., Padmanabhan, K., Marek, M., Stoll, I., Roy, L., Reilly, P.T., Mak, T.W., Dimitrov, S., Romier, C. and Hamiche, A. (2014) ANP32E Is a Histone Chaperone That Removes H2A.Z from Chromatin. Nature, 505, 648-653. http://dx.doi.org/10.1016/j.molcel.2006.12.015

[14] Goldberg, A.D., Banaszynski, L.A., Noh, K.M., Lewis, P.W., Elsaesser, S.J., Stadler, S., Dewell, S., Law, M., Guo, X., Li, X., Wen, D., Chapgier, A., DeKelver, R.C., Miller, J.C., Lee, Y.L., Boydston, E.A., Holmes, M.C., Gregory, P.D., Greally, J.M., Rafii, S., Yang, C., Scambler, P.J., Garrick, D., Gibbons, R.J., Higgs, D.R., Cristea, I.M., Urnov, F.D., Zheng, D. and Allis, C.D. (2010) Distinct Factors Control Histone Variant H3.3 Localization at Specific Genomic Regions. Cell, 140, 678-691. http://dx.doi.org/10.1016/j.cell.2010.01.003

[15] Shintomi, K., Iwabuchi, M., Saeki, H., Ura, K., Kishimoto, T. and Ohsumi, K. (2005) Nucleosome Assembly Protein-1 Is a Linker Histone Chaperone in Xenopus Eggs. Proceedings of the National Academy of Sciences of the United States of America, 102, 8210-8215. http://dx.doi.org/10.1073/pnas.0500822102

[16] Wade, P.A. and Kikyo, N. (2002) Chromatin Remodeling in Nuclear Cloning. European Journal of Biochemistry, 269, 2284-2287. http://dx.doi.org/10.1046/j.1432-1033.2002.02887.X

[17] Gadad, S.S., Senapati, P., Syed, S.H., Rajan, R.E., Shandilya, J., Swaminathan, V., Chatterjee, S., Colombo, E., Dimitrov, S., Pelicci, P.G., Ranga, U. and Kundu, T.K. (2011) The Multifunctional Protein Nucleophosmin (NPM1) Is a Human Linker Histone H1 Chaperone. Biochemistry, 50, 2780-2789. http://dx.doi.org/10.1021/bi101835j

[18] Angelov, D., Bondarenko, V.A., Almagro, S., Menoni, H., Mongelard, F., Hans, F., Mietton, F., Studitsky, V.M., Hamiche, A., Dimitrov, S. and Bouvet, P. (2006) Nucleolin Is a Histone Chaperone with FACT-Like Activity and Assists Remodeling of Nucleosomes. EMBO Journal, 25, 1669-1679. http://dx.doi.org/10.1038/sj.emboj.7601046

[19] Park, Y.J. and Luger, K. (2006) The Structure of Nucleosome Assembly Protein 1. Proceedings of the National Academy of Sciences of the United States of America, 103, 1248-1253. http://dx.doi.org/10.1073/pnas.0508002103

[20] van Dijk, J., Miro, J., Strub, J.M., Lacroix, B., van Dorsselaer, A., Edde, B. and Janke, C. (2008) Polyglutamylation Is a Post-Translational Modification with a Broad Range of Substrates. Journal of Biological Chemistry, 283, 3915-3922. http://dx.doi.org/10.1074/jbc.M705813200

[21] Daganzo, S.M., Erzberger, J.P., Lam, W.M., Skordalakes, E., Zhang, R., Franco, A.A., Brill, S.J., Adams, P.D., Berger, J.M. and Kaufman, P.D. (2003) Structure and Function of the Conserved Core of Histone Deposition Protein Asf1. Current Biology, 13, 2148-2158. http://dx.doi.org/10.1016/j.cub.2003.11.027

[22] DeSilva, H., Lee, K. and Osley, M.A. (1998) Functional Dissection of Yeast Hir1p, a WD Repeat-Containing Transcriptional Corepressor. Genetics, 148, 657-667.

[23] Kaufman, P.D., Kobayashi, R., Kessler, N. and Stillman, B. (1995) The p150 and p60 Subunits of Chromatin Assembly Factor I: A Molecular Link between Newly Synthesized Histones and DNA Replication. Cell, 81, 1105-1114. http://dx.doi.org/10.1016/S0092-8674(05)80015-7

[24] Muto, S., Senda, M., Akai, Y., Sato, L., Suzuki, T., Nagai, R., Senda, T. and Horikoshi, M. (2007) Relationship between the Structure of SET/TAF-I $\beta /$ INHAT and Its Histone Chaperone Activity. Proceedings of the National Academy of Sciences of the United States of America, 104, 4285-4290. http://dx.doi.org/10.1073/pnas.0603762104

[25] Park, Y.J. and Luger, K. (2008) Histone Chaperones in Nucleosome Eviction and Histone Exchange. Current Opinion in Structural Biology, 18, 282-289. http://dx.doi.org/10.1016/j.sbi.2008.04.003

[26] Gambus, A., Jones, R.C., Sanchez-Diaz, A., Kanemaki, M., van Deursen, F., Edmondson, R.D. and Labib, K. (2006) GINS Maintains Association of Cdc45 with MCM in Replisome Progression Complexes at Eukaryotic DNA Replication Forks. Nature Cell Biology, 8, 358-366.

[27] Groth, A., Corpet, A., Cook, A.J., Roche, D., Bartek, J., Lukas, J. and Almouzni, G. (2007) Regulation of Replication Fork Progression through Histone Supply and Demand. Science, 318, 1928-1931. http://dx.doi.org/10.1126/science.1148992

[28] Tan, B.C., Chien, C.T., Hirose, S. and Lee, S.C. (2006) Functional Cooperation between FACT and MCM Helicase Facilitates Initiation of Chromatin DNA Replication. EMBO Journal, 25, 3975-3985. http://dx.doi.org/10.1038/sj.emboj.7601271

[29] Jasencakova, Z., Scharf, A.N., Ask, K., Corpet, A., Imhof, A., Almouzni, G. and Groth, A. (2010) Replication Stress 
Interferes with Histone Recycling and Predeposition Marking of New Histones. Molecular Cell, 37, 736-743. http://dx.doi.org/10.1016/j.molcel.2010.01.033

[30] Adkins, M.W., Carson, J.J., English, C.M., Ramey, C.J. and Tyler, J.K. (2007) The Histone Chaperone Anti-Silencing Function 1 Stimulates the Acetylation of Newly Synthesized Histone H3 in S-Phase. Journal of Biological Chemistry, 282, 1334-1340. http://dx.doi.org/10.1074/jbc.M608025200

[31] Rolef Ben-Shahar, T., Castillo, A.G., Osborne, M.J., Borden, K.L., Kornblatt, J. and Verreault, A. (2009) Two Fundamentally Distinct PCNA Interaction Peptides Contribute to Chromatin Assembly Factor 1 Function. Molecular and Cellular Biology, 29, 6353-6365. http://dx.doi.org/10.1128/MCB.01051-09

[32] Mello, J.A., Sillje, H.H., Roche, D.M., Kirschner, D.B., Nigg, E.A. and Almouzni, G. (2002) Human Asf1 and CAF-1 Interact and Synergize in a Repair-Coupled Nucleosome Assembly Pathway. EMBO Reports, 3, 329-334. http://dx.doi.org/10.1093/embo-reports/kvf068

[33] Lee, C.K., Shibata, Y., Rao, B., Strahl, B.D. and Lieb, J.D. (2004) Evidence for Nucleosome Depletion at Active Regulatory Regions Genome-Wide. Nature Genetics, 36, 900-905. http://dx.doi.org/10.1038/ng1400

[34] Selth, L.A., Sigurdsson, S. and Svejstrup, J.Q. (2010) Transcript Elongation by RNA Polymerase II. Annual Review of Biochemistry, 79, 271-293. http://dx.doi.org/10.1146/annurev.biochem.78.062807.091425

[35] Cho, E.J., Kobor, M.S., Kim, M., Greenblatt, J. and Buratowski, S. (2001) Opposing Effects of Ctk1 Kinase and Fcp1 Phosphatase at Ser 2 of the RNA Polymerase II C-Terminal Domain. Genes \& Development, 15, 3319-3329. http://dx.doi.org/10.1101/gad.935901

[36] Lee, J.S. and Shilatifard, A. (2007) A Site to Remember: H3K36 Methylation a Mark for Histone Deacetylation. Mutation Research, 618, 130-134. http://dx.doi.org/10.1016/j.mrfmmm.2006.08.014

[37] Xue, Y.M., Kowalska, A.K., Grabowska, K., Przybyt, K., Cichewicz, M.A., Del Rosario, B.C. and Pemberton, L.F. (2013) Histone Chaperones Nap1 and Vps75 Regulate Histone Acetylation during Transcription Elongation. Molecular and Cellular Biology, 33, 1645-1656. http://dx.doi.org/10.1128/MCB.01121-12

[38] Duina, A.A., Rufiange, A., Bracey, J., Hall, J., Nourani, A. and Winston, F. (2007) Evidence That the Localization of the Elongation Factor Spt16 across Transcribed Genes Is Dependent upon Histone H3 Integrity in Saccharomyces cerevisiae. Genetics, 177, 101-112. http://dx.doi.org/10.1534/genetics.106.067140

[39] Aguilera, A. and Garcia-Muse, T. (2012) R Loops: From Transcription Byproducts to Threats to Genome Stability. Molecular Cell, 46, 115-124. http://dx.doi.org/10.1016/j.molcel.2012.04.009

[40] Ahmad, K. and Henikoff, S. (2002) The Histone Variant H3.3 Marks Active Chromatin by Replication-Independent Nucleosome Assembly. Molecular Cell, 9, 1191-1200. http://dx.doi.org/10.1016/S1097-2765(02)00542-7

[41] Schwabish, M.A. and Struhl, K. (2006) Asf1 Mediates Histone Eviction and Deposition during Elongation by RNA Polymerase II. Molecular Cell, 22, 415-422. http://dx.doi.org/10.1016/j.molcel.2006.03.014

[42] Jenuwein, T. and Allis, C.D. (2001) Translating the Histone Code. Science, 293, 1074-1080. http://dx.doi.org/10.1126/science.1063127

[43] Yang, J.H., Choi, J.H., Jang, H., Park, J.Y., Han, J.W., Youn, H.D. and Cho, E.J. (2011) Histone Chaperones Cooperate to Mediate Mef2-Targeted Transcriptional Regulation during Skeletal Myogenesis. Biochemical and Biophysical Research Communications, 407, 541-547. http://dx.doi.org/10.1016/j.bbrc.2011.03.055

[44] Yang, J.H., Song, Y., Seol, J.H., Park, J.Y., Yang, Y.J., Han, J.W., Youn, H.D. and Cho, E.J. (2011) Myogenic Transcriptional Activation of MyoD Mediated by Replication-Independent Histone Deposition. Proceedings of the National Academy of Sciences of the United States of America, 108, 85-90. http://dx.doi.org/10.1073/pnas.1009830108

[45] Black, B.L. and Olson, E.N. (1998) Transcriptional Control of Muscle Development by Myocyte Enhancer Factor-2 (MEF2) Proteins. Annual Review of Cell and Developmental Biology, 14, 167-196. http://dx.doi.org/10.1146/annurev.cellbio.14.1.167

[46] Roberts, C., Sutherland, H.F., Farmer, H., Kimber, W., Halford, S., Carey, A., Brickman, J.M., Wynshaw-Boris, A. and Scambler, P.J. (2002) Targeted Mutagenesis of the Hira Gene Results in Gastrulation Defects and Patterning Abnormalities of Mesoendodermal Derivatives Prior to Early Embryonic Lethality. Molecular and Cellular Biology, 22, 2318-2328. http://dx.doi.org/10.1128/MCB.22.7.2318-2328.2002

[47] Song, T.Y., Yang, J.H., Park, J.Y., Song, Y., Han, J.W., Youn, H.D. and Cho, E.J. (2012) The Role of Histone Chaperones in Osteoblastic Differentiation of C2C12 Myoblasts. Biochemical and Biophysical Research Communications, 423, 726-732. http://dx.doi.org/10.1016/j.bbrc.2012.06.026

[48] Dutta, D., Ray, S., Home, P., Saha, B., Wang, S., Sheibani, N., Tawfik, O., Cheng, N. and Paul, S. (2010) Regulation of Angiogenesis by Histone Chaperone HIRA-Mediated Incorporation of Lysine 56-Acetylated Histone H3.3 at Chromatin Domains of Endothelial Genes. Journal of Biological Chemistry, 285, 41567-41577. http://dx.doi.org/10.1074/jbc.M110.190025 
[49] Drane, P., Ouararhni, K., Depaux, A., Shuaib, M. and Hamiche, A. (2010) The Death-Associated Protein DAXX Is a Novel Histone Chaperone Involved in the Replication-Independent Deposition of H3.3. Genes \& Development, 24, 1253-1265. http://dx.doi.org/10.1101/gad.566910

[50] Wong, L.H., McGhie, J.D., Sim, M., Anderson, M.A., Ahn, S., Hannan, R.D., George, A.J., Morgan, K.A., Mann, J.R. and Choo, K.H. (2010) ATRX Interacts with H3.3 in Maintaining Telomere Structural Integrity in Pluripotent Embryonic Stem Cells. Genome Research, 20, 351-360. http://dx.doi.org/10.1101/gr.101477.109

[51] Kappes, F., Waldmann, T., Mathew, V., Yu, J., Zhang, L., Khodadoust, M.S., Chinnaiyan, A.M., Luger, K., Erhardt, S., Schneider, R. and Markovitz, D.M. (2011) The DEK Oncoprotein Is a Su(var) that Is Essential to Heterochromatin Integrity. Genes \& Development, 25, 673-678. http://dx.doi.org/10.1101/gad.2036411

[52] Corpet, A., De Koning, L., Toedling, J., Savignoni, A., Berger, F., Lemaitre, C., O’Sullivan, R.J., Karlseder, J., Barillot, E., Asselain, B., Sastre-Garau, X. and Almouzni, G. (2011) Asf1b, the Necessary Asf1 Isoform for Proliferation, Is Predictive of Outcome in Breast Cancer. EMBO Journal, 30, 480-493. http://dx.doi.org/10.1038/emboj.2010.335

[53] Staibano, S., Mascolo, M., Mancini, F.P., Kisslinger, A., Salvatore, G., Di Benedetto, M., Chieffi, P., Altieri, V., Prezioso, D., Ilardi, G., De Rosa, G. and Tramontano, D. (2009) Overexpression of Chromatin Assembly Factor-1 (CAF-1) p60 Is Predictive of Adverse Behaviour of Prostatic Cancer. Histopathology, 54, 580-589. http://dx.doi.org/10.1111/j.1365-2559.2009.03266.x

[54] Polo, S.E., Theocharis, S.E., Grandin, L., Gambotti, L., Antoni, G., Savignoni, A., Asselain, B., Patsouris, E. and Almouzni, G. (2010) Clinical Significance and Prognostic Value of Chromatin Assembly Factor-1 Overexpression in Human Solid Tumours. Histopathology, 57, 716-724. http://dx.doi.org/10.1111/j.1365-2559.2010.03681.x

[55] Alekseev, O.M., Richardson, R.T., Tsuruta, J.K. and O’Rand, M.G. (2011) Depletion of the Histone Chaperone tNASP Inhibits Proliferation and Induces Apoptosis in Prostate Cancer PC-3 Cells. Reproductive Biology and Endocrinology, 9, 50. http://dx.doi.org/10.1186/1477-7827-9-50

[56] Gasparian, A.V., Burkhart, C.A., Purmal, A.A., Brodsky, L., Pal, M., Saranadasa, M., Bosykh, D.A., Commane, M., Guryanova, O.A., Pal, S., Safina, A., Sviridov, S., Koman, I.E., Veith, J., Komar, A.A., Gudkov, A.V. and Gurova,

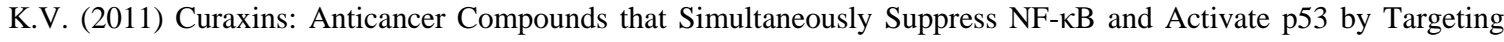
FACT. Science Translational Medicine, 3, 95ra74. http://dx.doi.org/10.1126/scitranslmed.3002530

[57] Koman, I.E., Commane, M., Paszkiewicz, G., Hoonjan, B., Pal, S., Safina, A., Toshkov, I., Purmal, A.A., Wang, D., Liu, S., Morrison, C., Gudkov, A.V. and Gurova, K.V. (2012) Targeting FACT Complex Suppresses Mammary Tumorigenesis in Her2/neu Transgenic Mice. Cancer Prevention Research, 5, 1025-1035. http://dx.doi.org/10.1158/1940-6207.CAPR-11-0529

[58] Garcia, H., Miecznikowski, J.C., Safina, A., Commane, M., Ruusulehto, A., Kilpinen, S., Leach, R.W., Attwood, K., Li, Y., Degan, S., Omilian, A.R., Guryanova, O., Papantonopoulou, O., Wang, J., Buck, M., Liu, S., Morrison, C. and Gurova, K.V. (2013) Facilitates Chromatin Transcription Complex Is an “Accelerator” of Tumor Transformation and Potential Marker and Target of Aggressive Cancers. Cell Reports, 4, 159-173. http://dx.doi.org/10.1016/j.celrep.2013.06.013

[59] Kurki, S., Peltonen, K., Latonen, L., Kiviharju, T.M., Ojala, P.M., Meek, D. and Laiho, M. (2004) Nucleolar Protein NPM Interacts with HDM2 and Protects Tumor Suppressor Protein p53 from HDM2-Mediated Degradation. Cancer Cell, 5, 465-475. http://dx.doi.org/10.1016/S1535-6108(04)00110-2

[60] Grisendi, S., Mecucci, C., Falini, B. and Pandolfi, P.P. (2006) Nucleophosmin and Cancer. Nature Reviews Cancer, 6, 493-505. http://dx.doi.org/10.1038/nrc1885

[61] Haferlach, C., Mecucci, C., Schnittger, S., Kohlmann, A., Mancini, M., Cuneo, A., Testoni, N., Rege-Cambrin, G., Santucci, A., Vignetti, M., Fazi, P., Martelli, M.P., Haferlach, T. and Falini, B. (2009) AML with Mutated NPM1 Carrying a Normal or Aberrant Karyotype Show Overlapping Biologic, Pathologic, Immunophenotypic, and Prognostic Features. Blood, 114, 3024-3032. http://dx.doi.org/10.1182/blood-2009-01-197871

[62] Yang, Y.F., Zhang, X.Y., Yang, M., He, Z.H., Peng, N.F., Xie, S.R. and Xie, Y.F. (2014) Prognostic Role of Nucleophosmin in Colorectal Carcinomas. Asian Pacific Journal of Cancer Prevention, 15, 2021-2026.

[63] Wise-Draper, T.M., Morreale, R.J., Morris, T.A., Mintz-Cole, R.A., Hoskins, E.E., Balsitis, S.J., Husseinzadeh, N., Witte, D.P., Wikenheiser-Brokamp, K.A., Lambert, P.F. and Wells, S.I. (2009) DEK Proto-Oncogene Expression Interferes with the Normal Epithelial Differentiation Program. American Journal of Pathology, 174, 71-81. http://dx.doi.org/10.2353/ajpath.2009.080330

[64] Wise-Draper, T.M., Mintz-Cole, R.A., Morris, T.A., Simpson, D.S., Wikenheiser-Brokamp, K.A., Currier, M.A., Cripe, T.P., Grosveld, G.C. and Wells, S.I. (2009) Overexpression of the Cellular DEK Protein Promotes Epithelial Transformation in Vitro and in Vivo. Cancer Research, 69, 1792-1799. http://dx.doi.org/10.1158/0008-5472.CAN-08-2304

[65] Soekarman, D., von Lindern, M., Daenen, S., de Jong, B., Fonatsch, C., Heinze, B., Bartram, C., Hagemeijer, A. and Grosveld, G. (1992) The Translocation (6;9) (p23;q34) Shows Consistent Rearrangement of Two Genes and Defines a Myeloproliferative Disorder with Specific Clinical Features. Blood, 79, 2990-2997. 
[66] Riveiro-Falkenbach, E. and Soengas, M.S. (2010) Control of Tumorigenesis and Chemoresistance by the DEK Oncogene. Clinical Cancer Research, 16, 2932-2938. http://dx.doi.org/10.1158/1078-0432.CCR-09-2330

[67] Jiao, Y., Shi, C., Edil, B.H., de Wilde, R.F., Klimstra, D.S., Maitra, A., Schulick, R.D., Tang, L.H., Wolfgang, C.L., Choti, M.A., Velculescu, V.E., Diaz Jr., L.A., Vogelstein, B., Kinzler, K.W., Hruban, R.H. and Papadopoulos, N. (2011) DAXX/ATRX, MEN1, and mTOR Pathway Genes Are Frequently Altered in Pancreatic Neuroendocrine Tumors. Science, 331, 1199-1203. http://dx.doi.org/10.1126/science.1200609

[68] Schwartzentruber, J., Korshunov, A., Liu, X.Y., Jones, D.T., Pfaff, E., Jacob, K., Sturm, D., Fontebasso, A.M., Quang, D.A., Tonjes, M., Hovestadt, V., Albrecht, S., Kool, M., Nantel, A., Konermann, C., Lindroth, A., Jager, N., Rausch, T., Ryzhova, M., Korbel, J.O., Hielscher, T., Hauser, P., Garami, M., Klekner, A., Bognar, L., Ebinger, M., Schuhmann, M.U., Scheurlen, W., Pekrun, A., Fruhwald, M.C., Roggendorf, W., Kramm, C., Durken, M., Atkinson, J., Lepage, P., Montpetit, A., Zakrzewska, M., Zakrzewski, K., Liberski, P.P., Dong, Z., Siegel, P., Kulozik, A.E., Zapatka, M., Guha, A., Malkin, D., Felsberg, J., Reifenberger, G., von Deimling, A., Ichimura, K., Collins, V.P., Witt, H., Milde, T., Witt, O., Zhang, C., Castelo-Branco, P., Lichter, P., Faury, D., Tabori, U., Plass, C., Majewski, J., Pfister, S.M. and Jabado, N. (2012) Driver Mutations in Histone H3.3 and Chromatin Remodelling Genes in Paediatric Glioblastoma. Nature, 482, 226-231. http://dx.doi.org/10.1038/nature10833

[69] Lorain, S., Demczuk, S., Lamour, V., Toth, S., Aurias, A., Roe, B.A. and Lipinski, M. (1996) Structural Organization of the WD Repeat Protein-Encoding Gene HIRA in the DiGeorge Syndrome Critical Region of Human Chromosome 22. Genome Research, 6, 43-50. http://dx.doi.org/10.1101/gr.6.1.43

[70] Farrell, M.J., Stadt, H., Wallis, K.T., Scambler, P., Hixon, R.L., Wolfe, R., Leatherbury, L. and Kirby, M.L. (1999) HIRA, a DiGeorge Syndrome Candidate Gene, Is Required for Cardiac Outflow Tract Septation. Circulation Research, 84, 127-135. http://dx.doi.org/10.1161/01.RES.84.2.127 